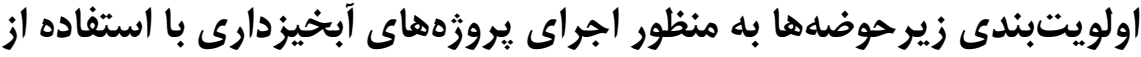

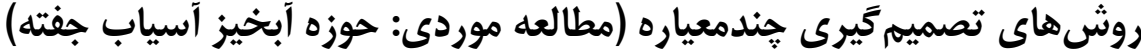

\author{
صديقه محمدى \\ كروه اكولوزى، يزوهشخاه علوم و تكنولوزى ييشرفته و علوم محيطى، دانشخاه تحصيلات تكميلى صنعتى و فناورى ييشرفنه، كرمان، ايران،

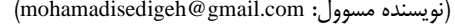

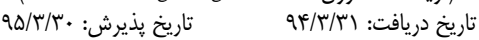

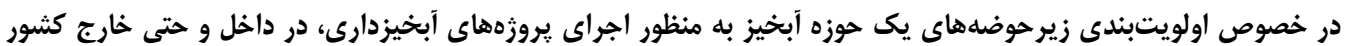

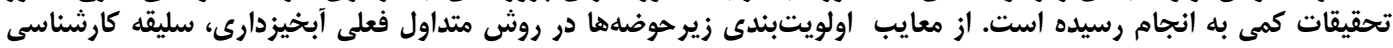

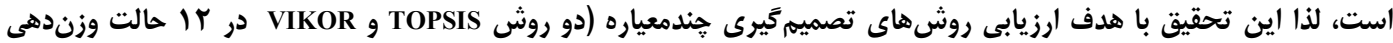

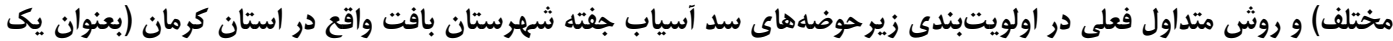

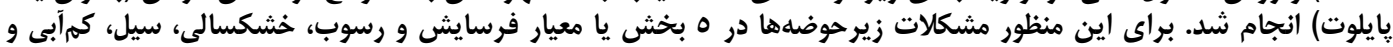

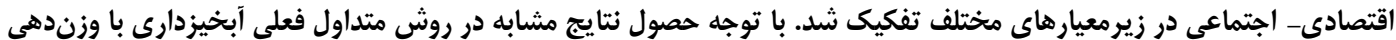

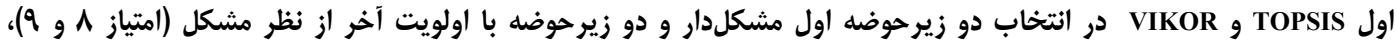

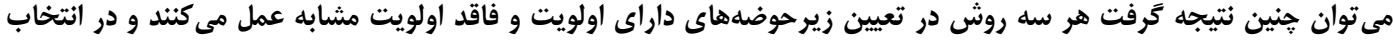

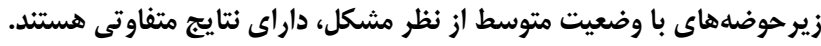

وازههاى كليدى: اولويتبندى، روش تصميمَيرى جندمعياره، زيرحوضه، سد بافت.

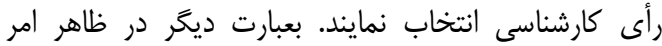

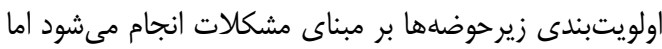

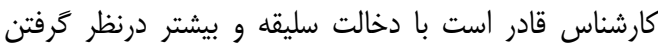

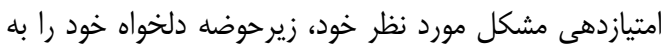

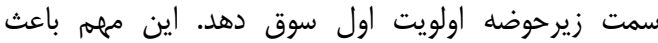

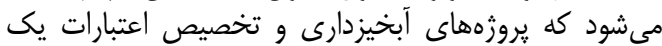

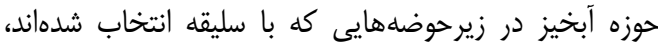

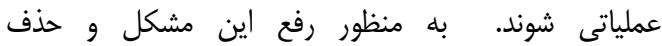

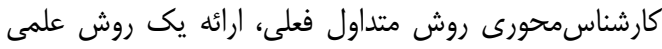

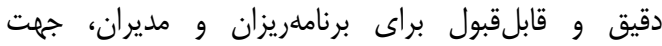

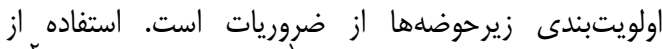

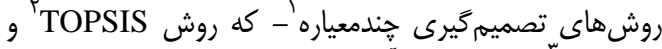

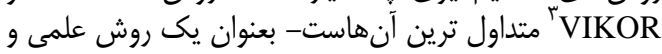

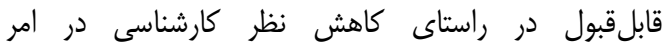

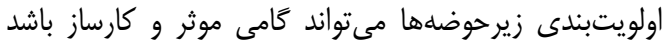

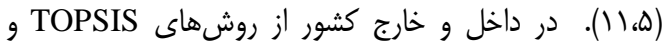

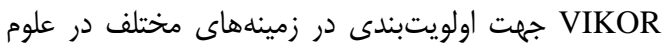

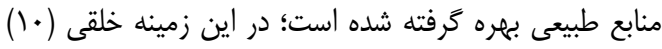

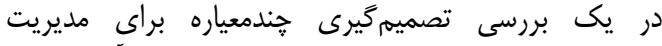
برناملريزى سيستمهاى مختلف فاضلاب و و تصفيه آن آن استفاده

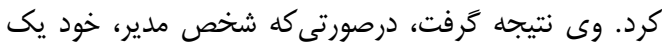

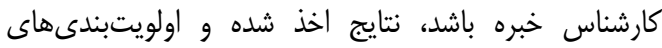

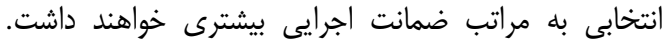

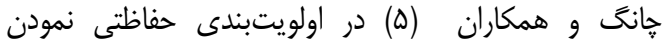

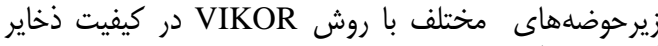

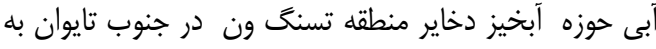

مقدمه

بدون شك ارائه يك برنامه جامع و كامل در يك حوزه

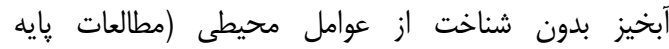

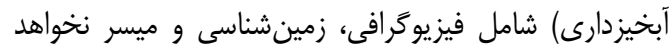

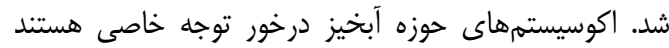

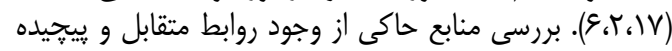

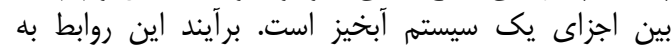

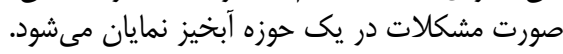

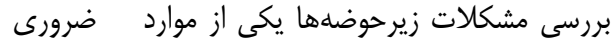

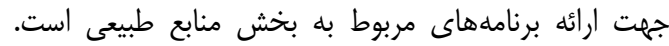

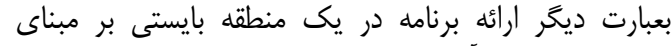

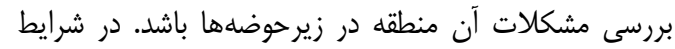

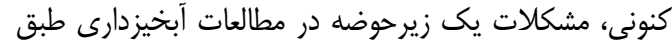

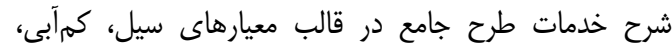

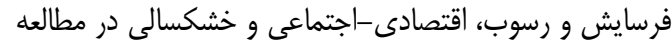

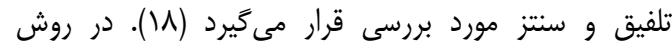

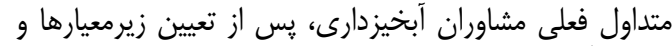

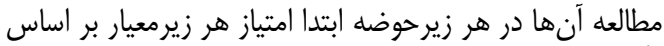

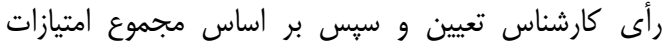

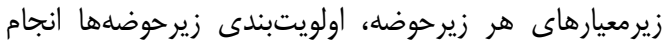

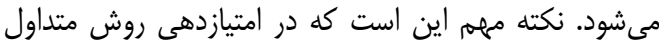

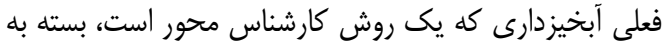

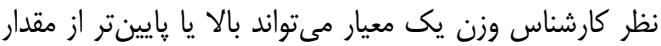

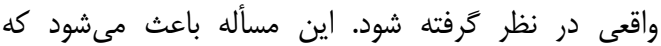

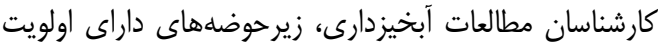

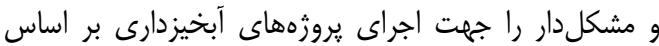


در رابطه با اولويتبندى زيرحوضهها در داخل كشور خلقى إنى

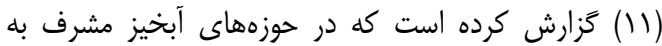

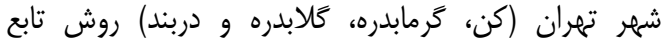

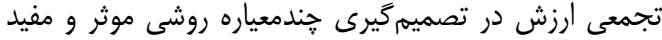
در اولويتبندى زيرحوضه إنهاست.

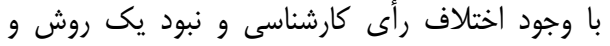

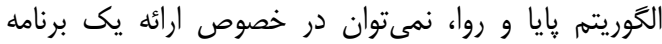

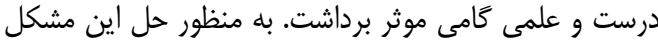

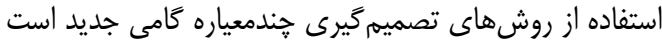

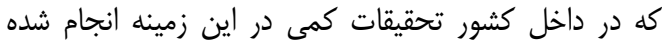

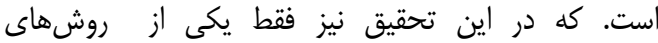

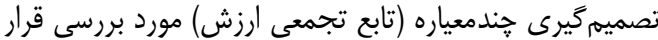

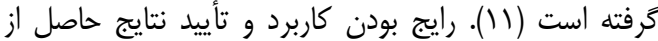
روشهاى TOPSIS و

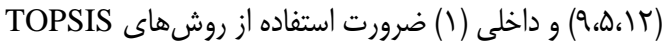

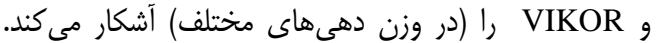

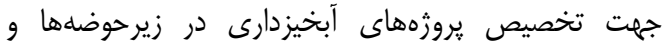
ولويتبندى آنها بر مبناى مشكلات، استفاده از علم رياضيات زئريات

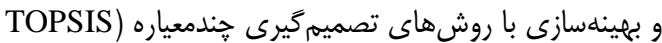

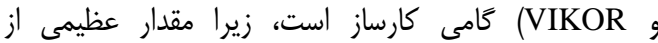

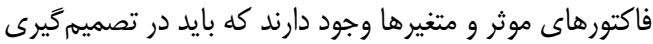

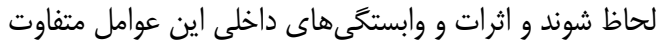

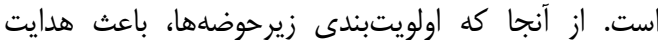

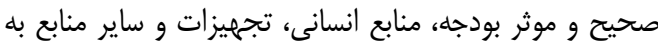

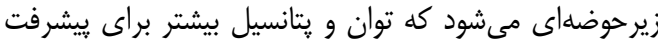

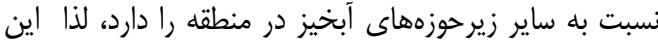

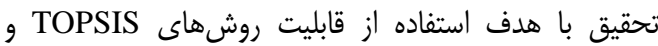

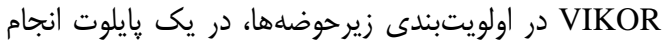

\section{مواد و روشها}

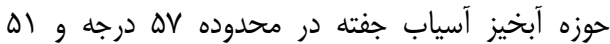

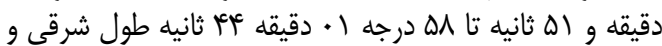

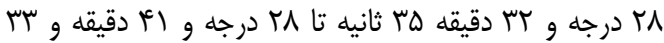

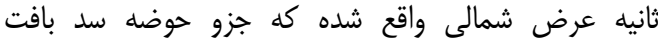

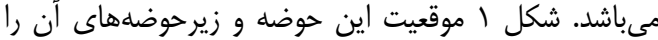

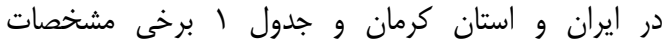
زيرحوضهها را نمايش مى أستان كرمان

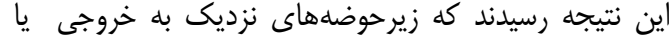

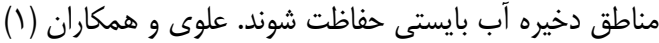

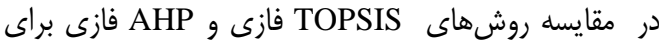

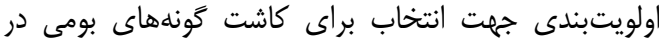

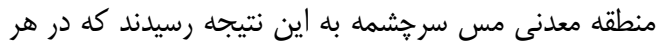

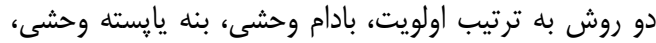

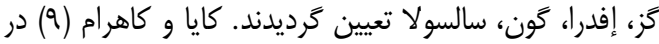

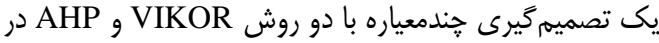

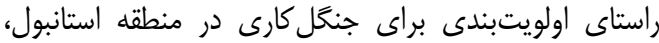

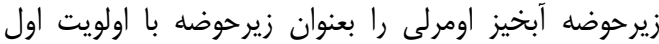

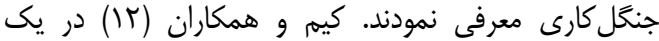
بررسى جهت اولويتبندى رودخانه جهت حوزه شهرى از روش

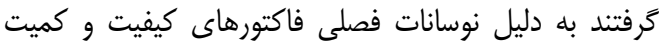

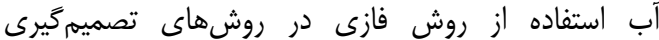

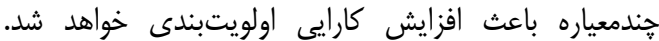

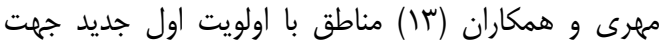

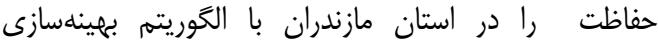

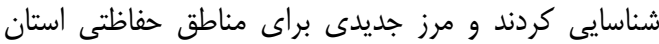

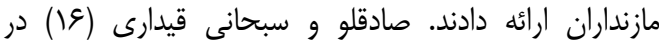

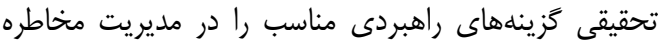
سيل با روش TOPSIS مورد بررسى قرار داريق دادند و نتيجه

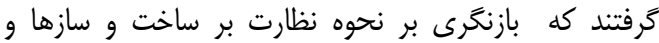

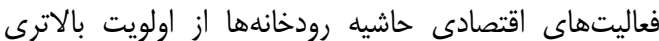

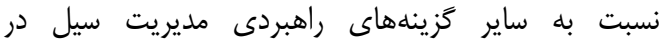

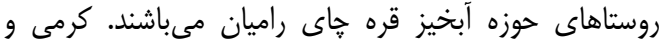

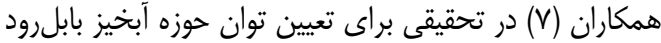

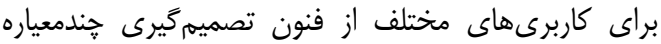

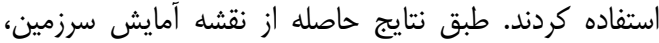

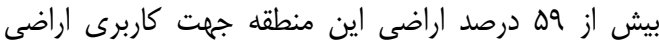

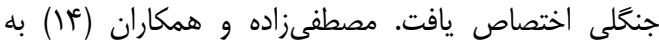

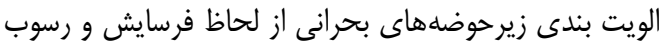

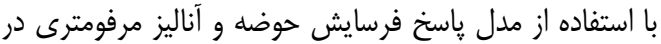

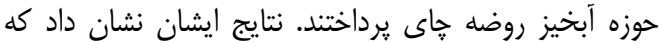

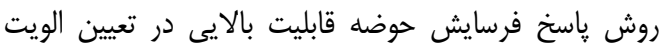

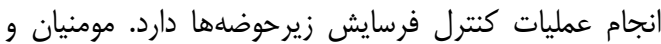

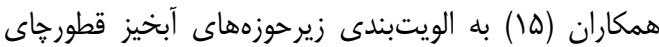

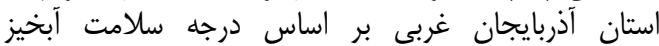
يرداختند. نتايج اين تحقيق حاكى إنى از آن آن است كه كليه

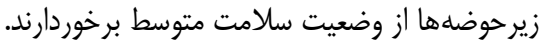



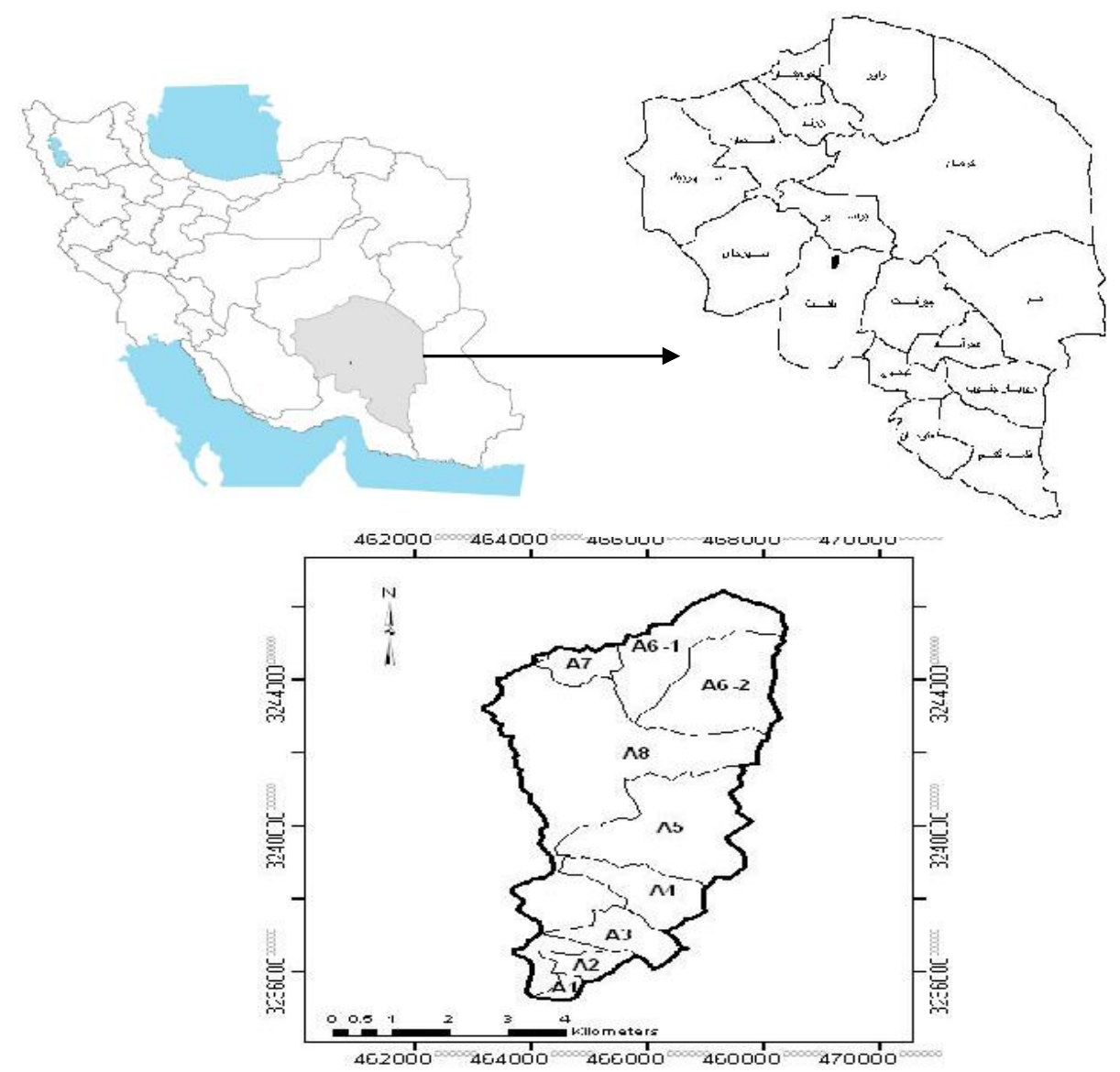

شكل ا- موقعيت حوزه آبخيز آسياب جفته و زيرحوضههاى آن در شهرستان بافت استان كرمان

Figure 1. Location of Asyabjofeth watershed and it's subwatersheds in Baft county of Kerman province

Table 1. Characterstics of studied subwatersheds

\begin{tabular}{|c|c|c|c|c|c|c|c|c|c|}
\hline \multirow{2}{*}{ حوضه } & \multicolumn{3}{|c|}{ مساحت تيب اراضى (هكتار) } & \multirow{2}{*}{ وزنفى (متر) } & \multirow{2}{*}{$\begin{array}{c}\text { متوسط بارندكى } \\
\text { (mm) }\end{array}$} & \multirow{2}{*}{$\begin{array}{c}\text { مرجه حرارت } \\
\text { متو }{ }^{\circ} \text { C }\end{array}$} & \multirow{2}{*}{ حماكثر مطلق } & \multirow{2}{*}{ مطلق دما } & \multirow{2}{*}{ 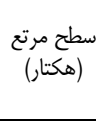 } \\
\hline & كوه & فلات و تراس & شكل سنكَريزه داري & & & & & & \\
\hline A) & $r \cdot / \Lambda$ & $\cdot$ & $\cdot / 0$ & TYQ./98 & $r \Lambda$. & 1.199 & $r / / \mathrm{V}$ & $-\mid \Psi / \Gamma \Lambda$ & $r I / \Psi V$ \\
\hline Ar & $v q / 9 q$ & • & · & $r \Delta I \cdot / 4 T$ & $r q v / 9$ & $1 \cdot / \pi 1$ & س שוא/M & $-\mid r / V$ & $v 9 / 99$ \\
\hline Ar & 109 & . & $r / \Delta$ & $T \Delta F \cdot / \Delta$ & $r \cdot N / V$ & $1 . / 1$. & $M / T r$ & $-1 \% / 9$ & $19 \% / \Delta$ \\
\hline Af & $M \mu$ & . & is & $r \Delta F / / \Lambda$ & $r \cdot q / r$ & 1.1 .9 & 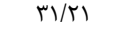 & $-|r / 9|$ & $T M N / T \Delta$ \\
\hline $\mathrm{A} \Delta$ & rQT & 9 & r & TASG/A & TIN/T & $9 / 91$ & mI/f & $-\mid \kappa / \cdot V$ & $\lceil\Delta \Lambda$ \\
\hline $\mathrm{A} \Lambda$ & QIT/A & GTF & $19 \cdot / 9$ & $r \Delta \Delta Q / \bar{q}$ & MIQ/द & १/१९ & $m / / .9$ & $-\mid F / . r$ & $\| 9 \Delta . f^{f}$ \\
\hline $\mathrm{AV}$ & ar & $9 / \Delta$ & $\cdot$ & rEI./1 & 吾 & $9 / 8$. & $r \cdot / V^{4}$ & - & $1 \cdot 1 / 9$ \\
\hline$A \varepsilon-r$ & rVI & $I V \cdot / \Lambda$ & $\cdot$ & rEFq/D & rFA & $9 / r$ & $r \cdot / \& V$ & $-|f / 8|$ & err \\
\hline $\left.\mathrm{A} \varepsilon_{-1}\right)$ & $\mid T N / T$ & $r \in \& / F$ & . & $r \varepsilon_{\Delta T / F}$ & req & $q / r$. & $r \cdot / \kappa \Delta$ & $-\mid f / g \mu$ & MFo/s \\
\hline
\end{tabular}

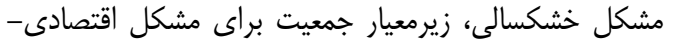

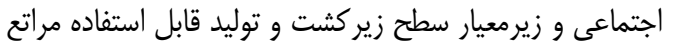

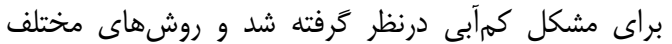

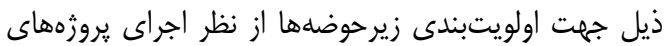

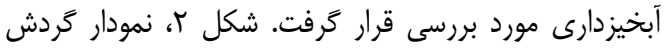
كار تحقيق را نمايش مى مئدهد.
جهت انجام اين تحقيق، ابتدا انتخاب معيارها و زير معير معيارها

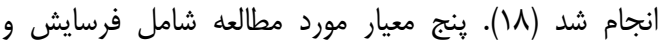

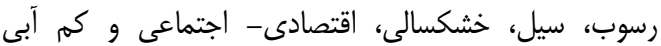

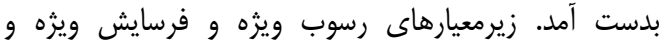

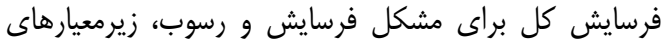

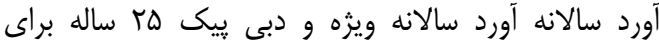
مشكل سيل، زيرمعيار تعداد منبع آبى و ميزان آبدهى دئ آن براى سئ سئ 


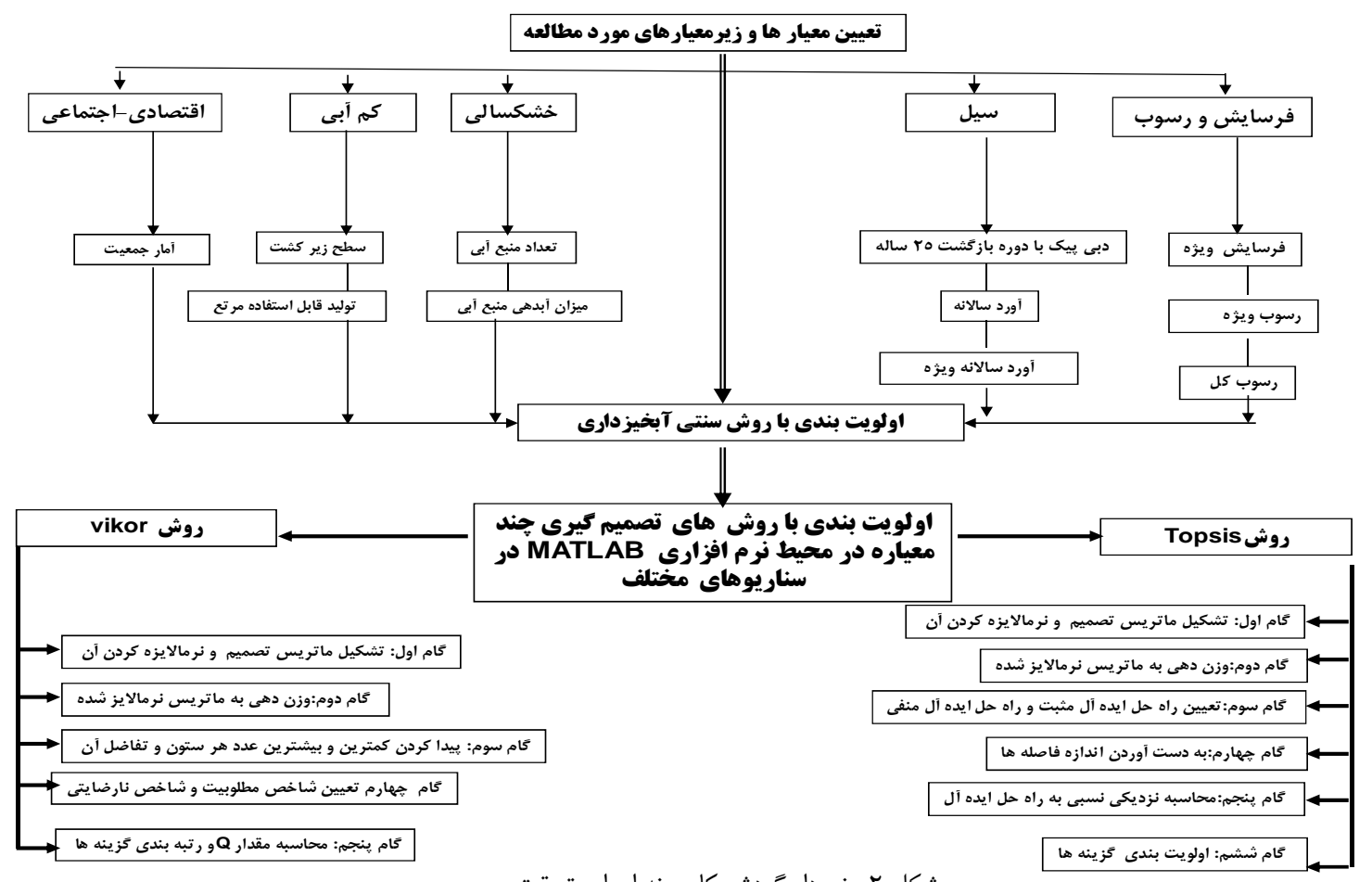

شكل r- نمودار گردش كار روند اجراى تحقيق

Figure 2. The research process flowchart

هر زيرحوضه منطقه مطالعاتى، امتياز نهايى زير حوضهها

بلدست آمد (1) (1).

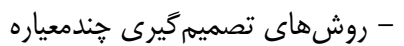

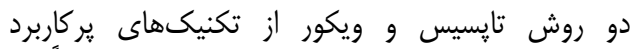

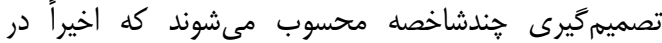

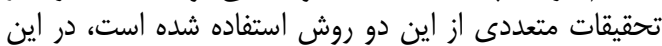

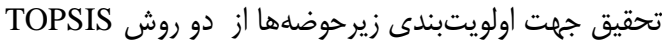

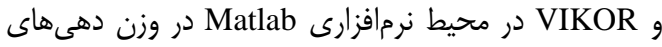

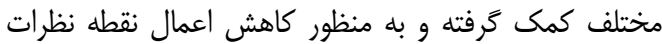

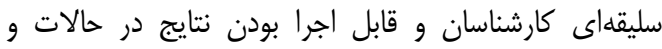

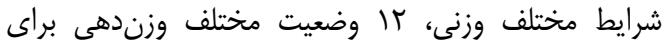

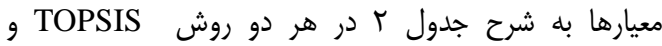
VIKOR
با توجه به هدف از اجراى اين تحقيق در راستاى مقايسه

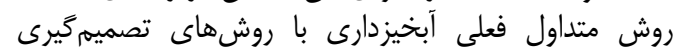

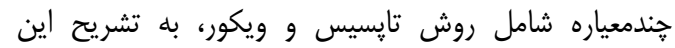

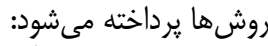
- روش متداول فعلى آبخيزدارى مانى

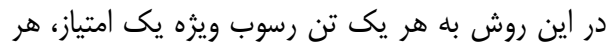

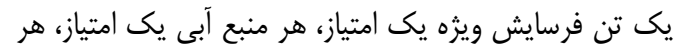

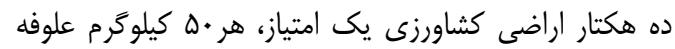

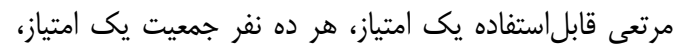

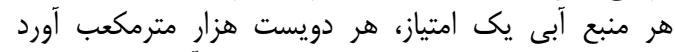

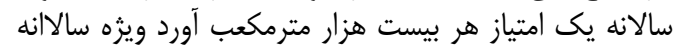

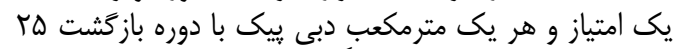

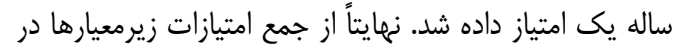

جدول r- وضعيتهاى مختلف وزندهى

Table 2. Different statuses of weighting

\begin{tabular}{|c|c|}
\hline شماره وضعيت وزندهى & 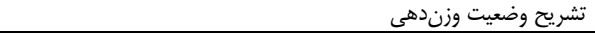 \\
\hline 1 & وزن تمامى معيارها بصورت مساوى \\
\hline r & وزن معيار فرسايش ويزه معادل •D درصد و مابقى معيارها •D درصد \\
\hline r & وزن معيار رسوب ويره معادل •D درصد و مابقى معيارها •ه درصد \\
\hline f & وزن معيار رسوب كل معادل •ه درصد و مابقى معيارها •ه درصد \\
\hline Q & وزن معيار منبع آبى معادل •D درصد و مابقى معيارها •ه درصد \\
\hline \& & وزن معيار ميزان آبدهى منابع معادل •ه درصد و مابقى معيارها •ه درصد \\
\hline$\checkmark$ & وزن معيار سطح زير كشت معادل •D درصد و مابقى معيارها •ه درصد \\
\hline$\wedge$ & وزن معيار توليد قابل استفاده معادل •ه درصد و مابقى معيارها •ه درصد \\
\hline 9 & وزن معيار جمعيت معادل •ه درصد و مابقى معيارها •ه درصد \\
\hline 1. & وزن معيار آورد سالانه معادل •ه درصد و مابقى معيارها •ه درصد \\
\hline 11 & وزن معيار آورد سالانه ويثه معادل •D درصد و مابقى معيارها •ه درصد \\
\hline ir & وزن معيار دبى ييك ما ساله معادل •D درصد و مابقى معيارها •ه درصد \\
\hline
\end{tabular}




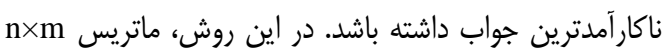

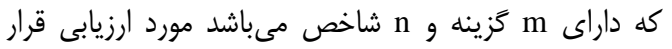

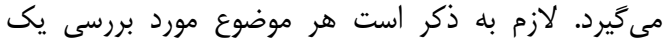

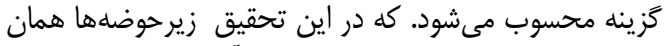

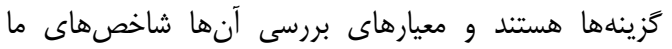

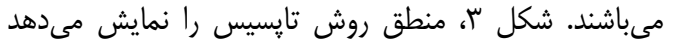

$(14.4)$
- روش TOPSIS -

تإيسيس به عنوان يك روش تصميمَّيرى جندشاخصه،

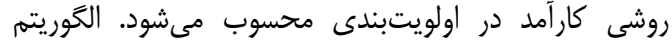

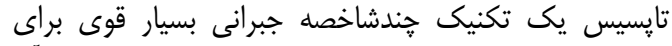

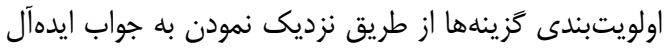

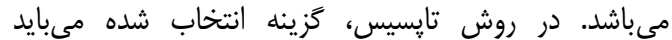
كوتاهترين فاصله را از جواب ايده آل و دورترين فاصله إناب را ازيل

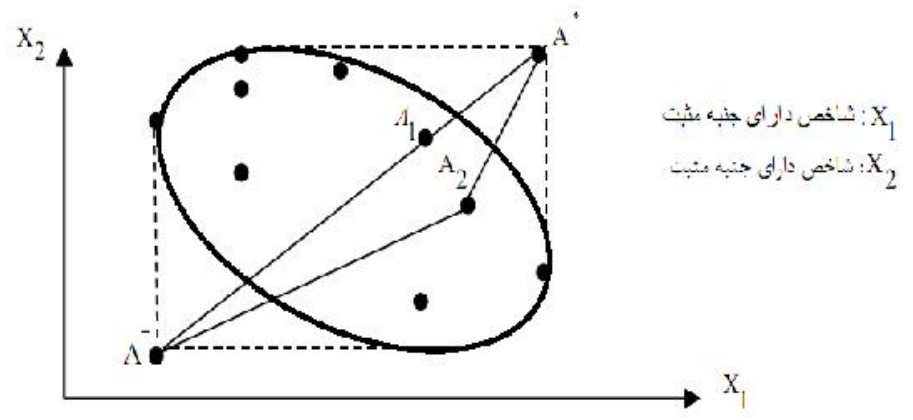

شكل ب- منطق روش تإيسيس (فاصله گز ينهها از ايده ال مثبت و منفى)

Figure 3. The logic of TOPSIS method (options distance from the positive and negative ideals)

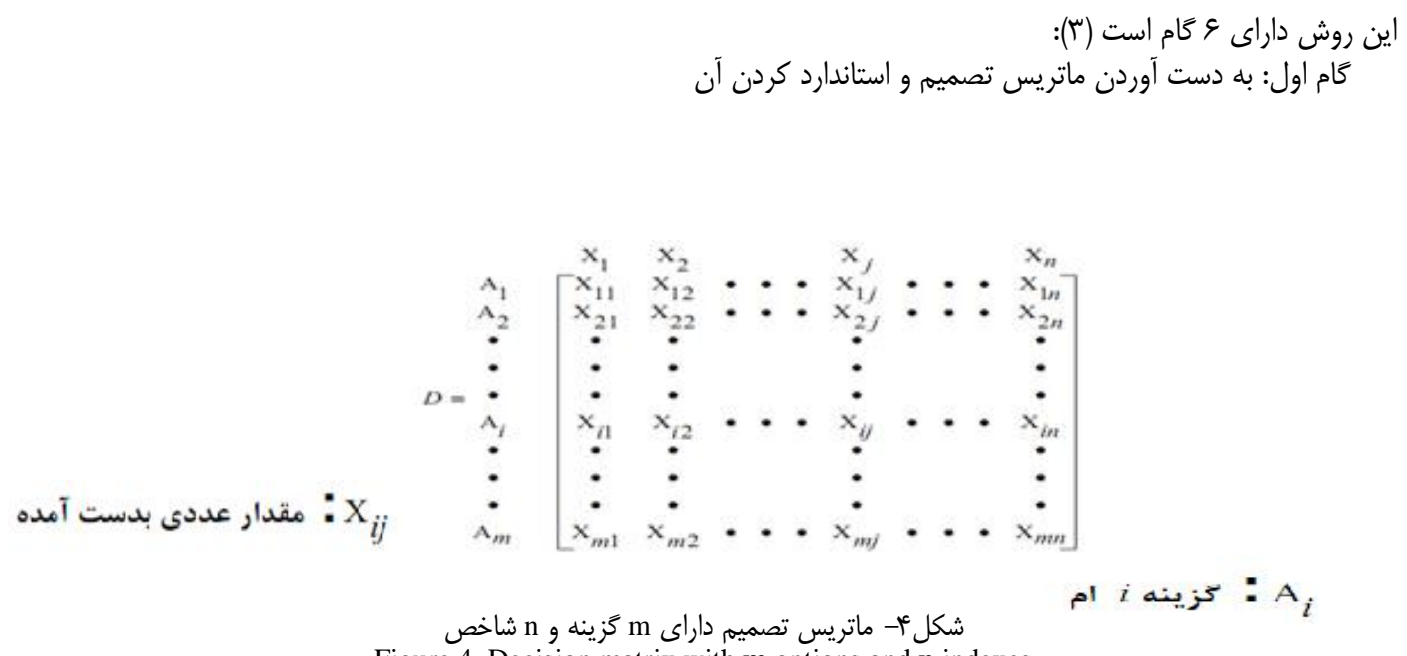

Figure 4. Decision matrix with $\mathbf{m}$ options and $\mathbf{n}$ indexes

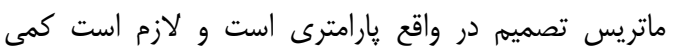

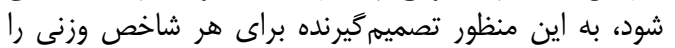

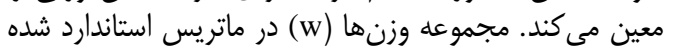
ضرب مىشود.

$$
\begin{aligned}
& W=\left(w_{1}, w_{2}, \ldots, w_{j}, \ldots, w_{n}\right) \\
& \sum{ }_{j=1}^{n} w_{j}=1
\end{aligned}
$$

جهت استانداردسازى ماتريس تصميم، مقياسهاى موجود در

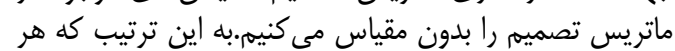

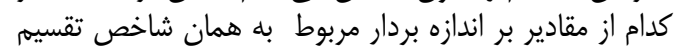

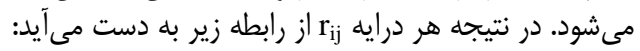

(r) $\quad r_{i j}=\frac{X_{i j}}{\sqrt{\sum_{i=1}^{m} X_{i j}^{2}}}$ 
كام سوم: تعيين راه حل ايدهآل مثبت و راه حل ايدهآل منفى

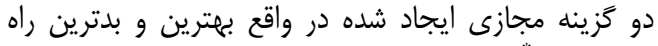

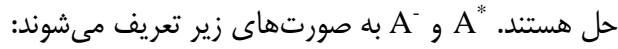

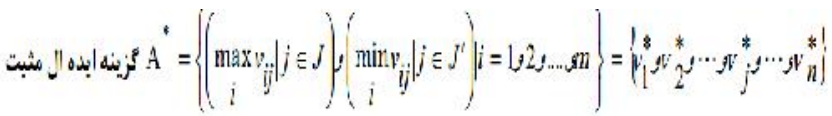

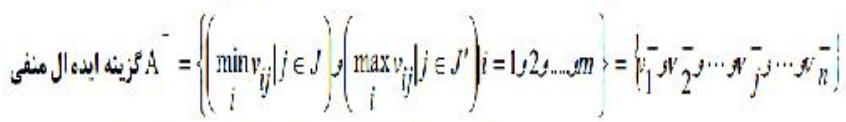

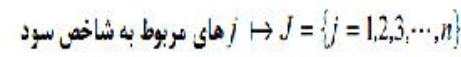

罗 $\mathrm{H} J^{\prime}=\{j=1,2,3, \cdots, n\}$

معيارها و با تركيب در ارزش معيارها، ارزيابى شده و رتبهبندى

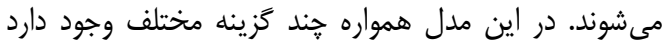

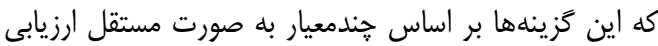

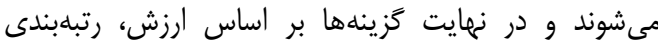

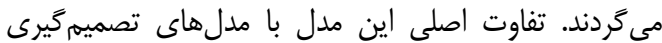

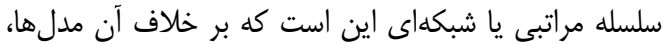

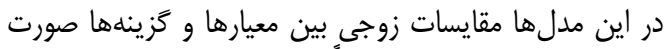

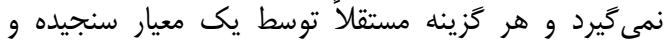

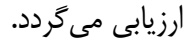

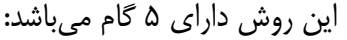
كام اول: تشكيل ماتريس تصميهم و نرمال مالرسازى آن آن

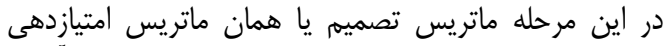

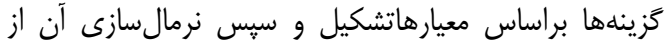

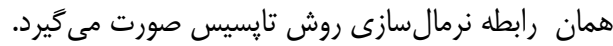

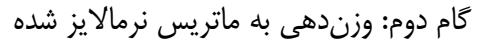

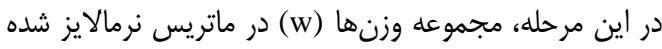

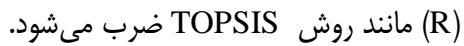

$$
R^{*}=\operatorname{MinRi}
$$

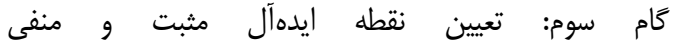

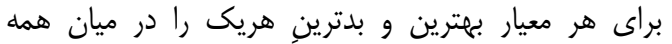

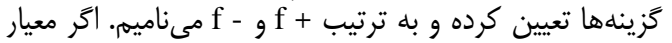
از نوع سودمندى باشد خواهيم داشت:

$f+=\operatorname{Maxf}_{i j}$

$f-=\operatorname{Min} f_{i j}$

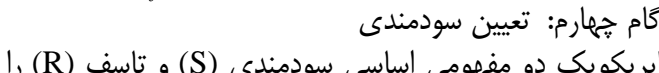

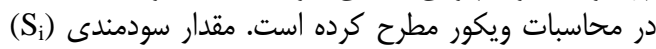

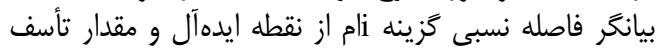

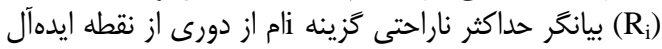

$$
R_{i}=\max \left[w_{j^{\prime}} \cdot \frac{f_{j^{*}}-f_{i j}}{f_{j^{*}}-f_{j^{-}}}\right]
$$

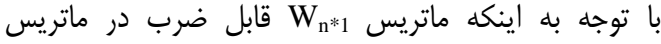

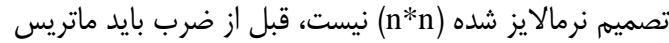

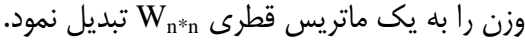

كام جهارم: بدست آوردن اندازه فاصلهها

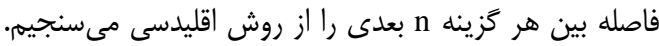

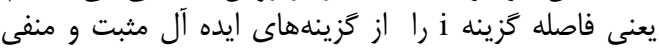

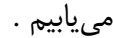

$$
\begin{aligned}
& S_{i^{*}}=\sqrt{\sum_{j=1}^{n}\left(\mathrm{v}_{i j}-\mathrm{v}^{*}{ }_{j}\right)^{2}} \\
& S_{i-}=\sqrt{\sum_{j=1}^{n}\left(\mathrm{v}_{i j}-\mathrm{v}^{-}{ }_{j}\right)^{2}} \\
& i=1,2,3, \ldots, \quad m
\end{aligned}
$$

كام بنجم : محاسبه نزديكى نسبى به راه حل ايدهآ آل اين معيار از طريق فرمول زير به دست منى آيد:

$$
C_{i^{*}}=\frac{S_{i-}}{S_{i^{*}}+S_{i^{-}}}
$$

$0<C_{i *}<1$

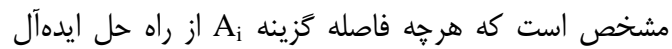

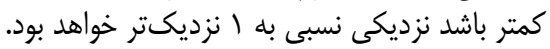

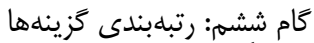

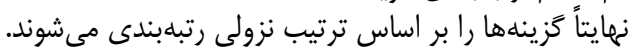

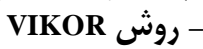
روش ويكور (VIKOR) يكى از مدلهاى بر كاربرد در

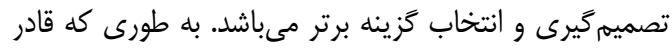

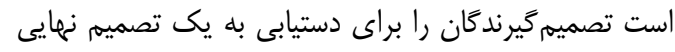

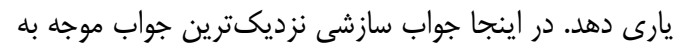

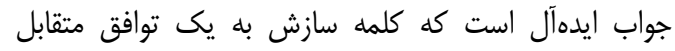

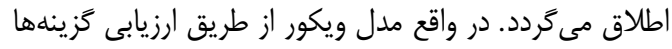

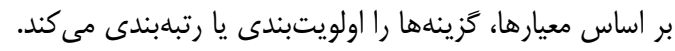

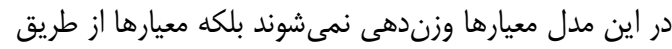

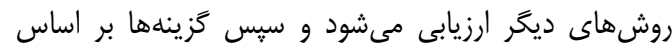




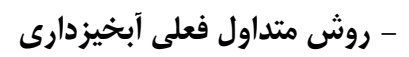

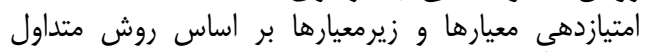

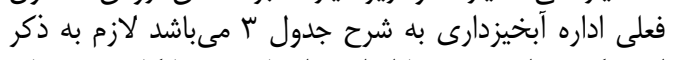

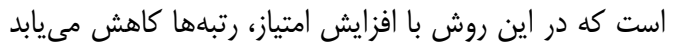

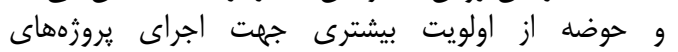
آبخيزدارى برخوردار مى كَردد.

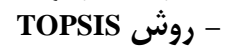

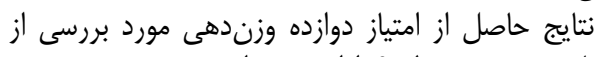

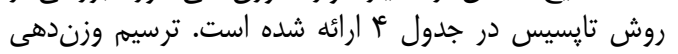

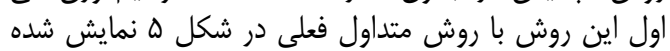

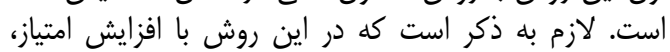

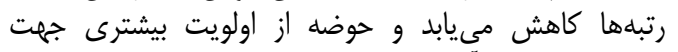
اجراى بروزههاى آبخيزدارى برخوردار مى كرددد.

$$
s_{i}=\sum_{j=1}^{n} w_{j} \cdot \frac{f_{j^{*}}-f_{i j}}{f_{j^{*}}-f_{j^{-}}}
$$

كام ينجم: محاسبه شاخص ويكور

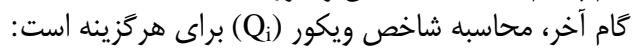

$$
Q_{i}=v\left[\frac{S_{i}-S^{*}}{S^{-}-S^{*}}\right]+(1-v)\left[\frac{R_{i}-R^{*}}{R^{-}-R^{*}}\right]
$$

$$
\begin{gathered}
S^{-}=\operatorname{MaxSi} \\
S^{*}=\operatorname{MinSi} \quad R^{-}=\operatorname{MaxRi}
\end{gathered}
$$

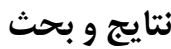

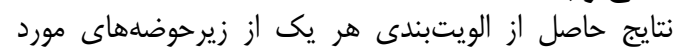

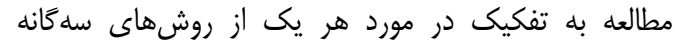

\begin{tabular}{|c|c|c|c|c|c|c|c|c|c|c|c|c|}
\hline زيرمع & فريز & رويزوب & رسوب & منبع & $\begin{array}{c}\text { ميزان أبدهى } \\
\text { منابع }\end{array}$ & سطح زير & توليد قابل & جمع & سالانه & أورد سالانه & 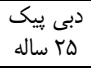 & امتيازات \\
\hline A) & f & $\Delta / \cdot 9$ & $\Gamma / \Delta \Lambda$ & . & . & • & $T / T$ & . & $\cdot 1 \cdot 1$ & $r / 89$ & $. / 91 /$ & 11 \\
\hline Ar & $\Delta / V$ & 91.9 & $1 r / q$ & . & . & . & $T / T$ & . &.$/ T F$ & $r / . r$ & ז/\%११ & r \\
\hline Ar & $8 / \Delta$ & $g / T$ & rq/G & . & . & . & $T / T$ & . & $\cdot / \Delta T$ & זTK/. & F/MFT & 49 \\
\hline Af & $r / 9$ & $F / T \Lambda$ & r & 1 & f & $1 / \pi$ & $T / T$ & . & $\cdot / V \mu$ & אוז/. & $r / \cdot 1$ & $\Delta F$ \\
\hline $\mathrm{A} \Delta$ & $g / 4$ & $\Delta$ & $1 . V$ & $r$ & r & $s / \pi$ & $1 / v 9$ & $1 . / V$ & $r / \cdot 1$ & . $/ F F \mid$ & $1 / \Lambda \Lambda$ & 190 \\
\hline $\mathrm{A \Lambda}$ & $\mathrm{V} / \mathrm{s}$ & $F / q$ & Tצ' & $r$ & זו & $1 / \Delta$ & $r / \cdot V$ & $r / \mu$ & F/ & צאץ/. & . & $r \cdot 1$ \\
\hline $\mathrm{AV}$ & $\tau / T$ & $F / \mu F$ & $\mid N / \Delta$ & . & . & - & $T / T$ & . & $\cdot / \mu \wedge$ & $\cdot / \% \vee \Delta$ & I/VG & TD \\
\hline $\begin{array}{c}A_{r}-g \\
r\end{array}$ & $g / 4$ & $\Delta$ & $\Lambda \cdot / V$ & - & . & $\cdot / V$ & $1 / 48$ & - & $1 / v 9$ & $\cdot / 4 \cdot 9$ & $F / T$ & $1 .$. \\
\hline$\underset{1-9}{A}$ & \&/8 & $\Delta / T \Lambda$ & $v \cdot / q$ & 1 & $\Delta$ & 1 & $1 / \Delta \Delta$ & • & I/AT & $\cdot|+|$ & $\Delta / \Delta$ & 91 \\
\hline
\end{tabular}

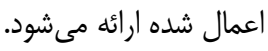

جدول بـ- امتيازات زيرحوضهها با روش متداول فعلى آبخيزدارى Table 3. Subwatershed scores with the current watershed management method

\begin{tabular}{|c|c|c|c|c|c|c|c|c|c|c|c|c|c|}
\hline & *وضعيت وزندهى & 1 & 2 & 3 & 4 & 5 & 6 & 7 & 8 & 9 & 10 & 11 & 12 \\
\hline \multirow{9}{*}{ امتياز } & A) &.$/ 199$ & •/AY & $\cdot / V^{c}$ &.$/ 94$ &.$/ 94$ &.$/ 94$ &.$/ 90$ &.$/ 8$. & .190 &.$/ 94$ &.$/ T V$ & ./AT \\
\hline & Ar & $\cdot / V \Delta$ &.$/ 94$ &.$/ 09$ &.$/ 94$ &.$/ 94$ & . &.$/ 94$ & $\cdot / \Delta \Lambda$ &.$/ 94$ &.$/ 94$ & אז/. &.$/ 09$ \\
\hline & Ar & $\cdot|\Lambda|$ & $\cdot / \Delta V$ & $\cdot / 8$. &.$/ 9$. &.$/ 94$ &.$/ 90$ &.$/ 90$ &.$/ 8$. & .199 & $\cdot / 199$ &.$/ 94$ & F \\
\hline & Af & $\cdot / \mathrm{V}$ & ./Va & $\cdot / \Lambda$ & $\cdot / M$ & $.19 \mathrm{~V}$ & $\cdot|\Lambda|$ & $\cdot / \Lambda$ & $\cdot / \Delta V$ &.$/ 90$ & $\cdot / \Lambda F$ & س & • \\
\hline & $\mathrm{A} \Delta$ & $\cdot / \mu$ & سس/. & سזא. & $\cdot / \Delta \Lambda$ & F &.$/ 1$ & .1 .9 & $\cdot|+|$ & .1 .9 & سم/. & $\cdot / \Lambda$. &.$/ 89$ \\
\hline & $\mathrm{A} \wedge$ & $\cdot / \& \wedge$ & צמ/. & $\cdot / D F$ & سו/. &.$/ 1 f^{2}$ & . Kt & $\cdot / V$ & سז/. & $\cdot / V q$ &.$/ 14$ & س ب/. & $\cdot|\Lambda|$ \\
\hline & AV &.$/ 91$ &.$/ 91$ &.$/ 94$ &.$/ 98$ &.$/ 9 V$ &.$/ 91$ &.$/ 91$ & .184 &.$/ 91$ & (9) & .198 & $\cdot / \mathrm{V}$ \\
\hline & $A \&-r$ &.$/ V q$ & $\cdot / \Delta S$ & $\cdot / V^{2}$ & $\cdot|n|$ & س &.$/ 94$ & $\cdot / M$ & $\cdot / v 9$ & .190 &.$|9|$ & .194 & سא/. \\
\hline & A $9-1$ & $\cdot / \mathrm{V}$ &.$|0|$ & .190 & $\cdot / v f$ & $.19 \mathrm{~V}$ & $\cdot / \mathrm{VV}$ & • & $\cdot / V^{f}$ & . & $.18 \mathrm{~V}$ & .19. & זr/. \\
\hline \multirow{9}{*}{ رتبه } & A) & $r$ & $r$ & $r$ & $r$ & $r$ & $r$ & $r$ & $\Delta$ & f & 1 & 1 & 1 \\
\hline & Ar & 9 & $f$ & V & r & $\Delta$ & $\Delta$ & f & 9 & 9 & r & 9 & $\Delta$ \\
\hline & Ar & $r$ & $\Delta$ & 9 & f & r & $r$ & $r$ & f & $r$ & f & r & $v$ \\
\hline & Af & f & r & $r$ & $\Delta$ & 9 & 9 & V & V & r & $\Delta$ & r & $\varepsilon$ \\
\hline & $\mathrm{A} \Delta$ & 9 & 9 & 9 & $\Lambda$ & $\wedge$ & 9 & 9 & 9 & 9 & $\Lambda$ & V & f \\
\hline & $\mathrm{A} \wedge$ & $\wedge$ & $\wedge$ & $\Lambda$ & 9 & 9 & $\wedge$ & $\wedge$ & $\wedge$ & $\wedge$ & 9 & 9 & r \\
\hline & AV & 1 & 1 & 1 & 1 & 1 & 1 & 1 & r & 1 & $r$ & 1 & r \\
\hline & $A E-r$ & $\Delta$ & $\varepsilon$ & f & V & f & $f$ & $\Delta$ & 1 & $\Delta$ & V & f & $\wedge$ \\
\hline & $A \&-1$ & $V$ & $V$ & $\Delta$ & 9 & $V$ & $V$ & 9 & $r$ & V & 9 & $\Delta$ & 9 \\
\hline
\end{tabular}

جدول f- تعيين امتياز و رتبه زيرحوضهها با روش TOPSIS Table 4. Determination of subwatershed scoring and ranking by TOPSIS method 
لازم به ذكر است كه در اين روش با افزايش امتياز، رتبهها

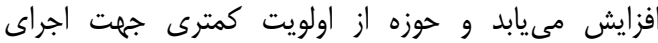

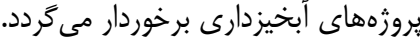

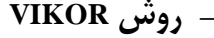

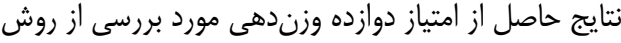

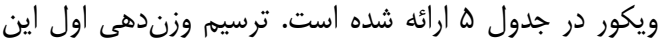
روش با روش متداول فعلى در شكل ه هن نمايش شده است.

جدول ه- تعيين امتياز و رتبه زيرحوضهها با روش VIKOR Table 5. Determination of subwatershed scoring and ranking by VIKOR method

\begin{tabular}{|c|c|c|c|c|c|c|c|c|c|c|c|c|c|}
\hline & *وضعيت وزندهى & 1 & 2 & 3 & 4 & 5 & 6 & 7 & 8 & 9 & 10 & 11 & 12 \\
\hline \multirow{9}{*}{ امتياز } & A) & $\cdot / 1 \wedge$ & . & (4/ & $.1 \cdot 4$ & .1 .9 & .1 .9 & .1 .9 & $\cdot / \wedge \mathrm{F}$ & .1 .9 & $.1 \cdot 1$ & $\cdot / \mathrm{VA}$ & . \\
\hline & Ar & $\cdot|\Delta|$ & $\cdot / \Delta T$ & .198 &.$/ 1 \mathrm{~V}$ &.$/ 1 \mathrm{~V}$ &.$/ 19$ &.$/ 19$ &.$/ 9 V$ & .119 & $\cdot / 10$ & 1 &.$/ 4 F$ \\
\hline & Ar & $\cdot / F V$ & .199 & 1 & $\cdot / 4$ & $\cdot / 10$ & $\cdot / 10$ & $\cdot / 10$ &.$/ 90$ & $\cdot / 10$ &.$/ 19$ &.$/ 1 \mathrm{~V}$ & $\cdot / \mathrm{VA}$ \\
\hline & Af & $\cdot / \mu$. & $\cdot / T \Delta$ & .1 .9 &.$/ 10$ & سس/. & (t/. & שr/. & $\cdot / 199$ &.$/ 1$. &.$/ 19$ &.$/ 1$. & $.18 \Delta$ \\
\hline & $\mathrm{A} \Delta$ & 1 & $\cdot / \Lambda \varepsilon$ & .199 & $\cdot / 9$. & $\cdot / v 9$ & 1 & 1 & $\cdot / v$ & 1 &.$/ 94$ & • & $\cdot / F \Delta$ \\
\hline & $\mathrm{A} \wedge$ &.$/ 97$ & 1 & $\cdot / 19 q$ & 1 & 1 & $\cdot / V \cdot$ & $\cdot / \& V$ & 1 & $\cdot / \notin \Delta$ & 1 & $\cdot / \pi \Delta$ & $\cdot / r$. \\
\hline & AV & • & $\cdot 1 \cdot 1$ & - & - & • & • & • & $\cdot / V 8$ & - & • & • & $\cdot / \cdot \mathrm{V}$ \\
\hline & $A \&-r$ & ./TA & .109 & - & $\cdot / T V$ & $\cdot 1 \cdot 1$ & $\cdot 1 \cdot 1$ &.$/ 19$ & • & $\cdot / \cdot 1$ & سז/. &.$/ 11$ & $.19 \mathrm{~V}$ \\
\hline & $\mathrm{A} 9-1$ &.$/ 4 V$ & $\cdot / V T$ & .19. & (r/. & ./4q & آו"/. & - &.$/ 19$ &.$/ 10$ & ع ع/א. & $\cdot / r$ & 1 \\
\hline \multirow{9}{*}{ رتبه } & A) & $r$ & 1 & $r$ & $r$ & $r$ & $r$ & $r$ & $\Delta$ & $r$ & $r$ & 1 & 1 \\
\hline & Ar & V & f & $\wedge$ & f & $\Delta$ & $\Delta$ & $\Delta$ & $\wedge$ & V & r & 9 & f \\
\hline & Ar & $\Delta$ & 9 & 9 & $\Delta$ & $f$ & f & r & V & $\Delta$ & $\Delta$ & f & $\Lambda$ \\
\hline & Af & $f$ & r & r & $r$ & 9 & 9 & 9 & 9 & r & f & $r$ & 9 \\
\hline & $\mathrm{A} \Delta$ & 9 & $\wedge$ & V & $\wedge$ & $\wedge$ & 9 & 9 & r & 9 & $\wedge$ & v & $\Delta$ \\
\hline & $\mathrm{A \Lambda}$ & $\wedge$ & 9 & $\Delta$ & 9 & 9 & V & $\Lambda$ & 9 & $\wedge$ & 9 & 9 & r \\
\hline & AV & 1 & r & 1 & 1 & 1 & $\wedge$ & 1 & f & 1 & 1 & 1 & r \\
\hline & $A \xi-r$ & r & $\Delta$ & f & 9 & r & $r$ & f & 1 & r & 9 & r & V \\
\hline & A $9-1$ & 9 & V & 9 & V & V & V & V & $r$ & 8 & V & $\Delta$ & 9 \\
\hline
\end{tabular}

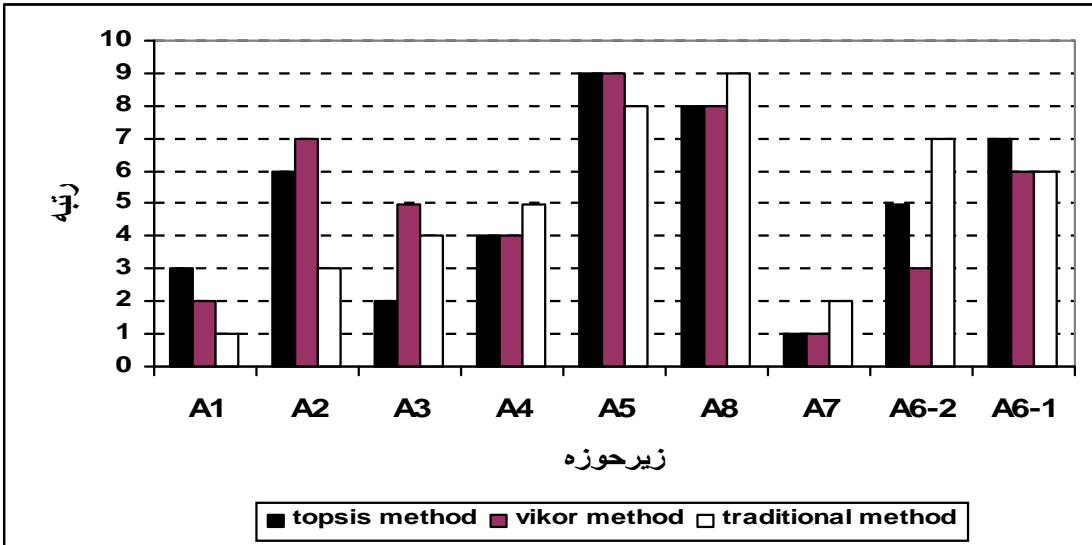

شكل ه- اولويتبندى زيرحوضهها تحت سناريوى اول (يكسان كرفتن وزن معيارها) در دو روش تايسيس و ويكور و مقايسه آنها با روش إِ متداول فعلى آبخيزدارى

Figure 5. Prioritization of subwatersheds under first scenario (same weighting of criterias) in two TOPSIS and VIKOR and comparing with current traditional watershed management method.

تعيين دو زيرحوضه اول داراى مشكل تأييد مىشود و دور

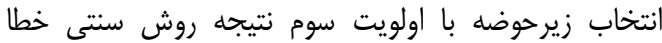
بوجود آمده است و نبايستى از روش سور متداول فعلى استفاده

$$
\text { شود. }
$$

نتايج اين تحقيق نشان داد كه با وزن دادن بيشتر به دبى

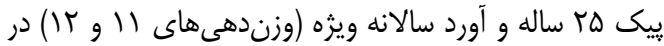

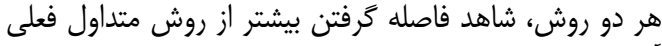

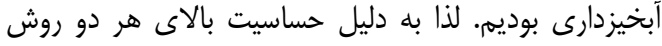

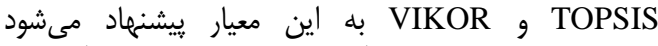
كارشناسان محترم و اداره آبخيزدارى در محاسبه ميار واسه و آناليز به اين معيارها توجه خاصى داشته واشن الشند.
نتايج حاصل از اولويتبندى با وزندهىهاى مختلف هر

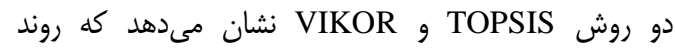

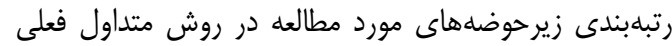

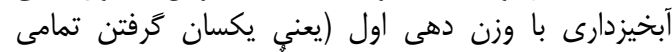

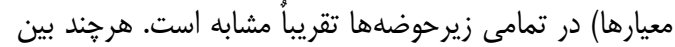

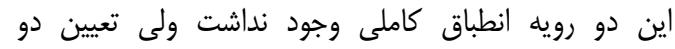

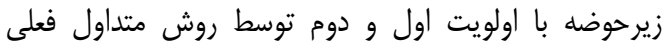

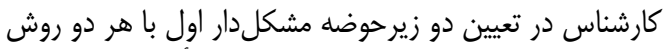

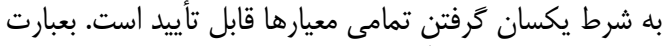

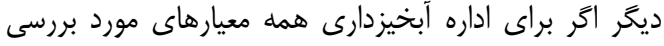

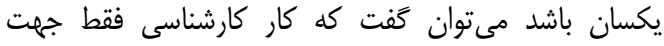




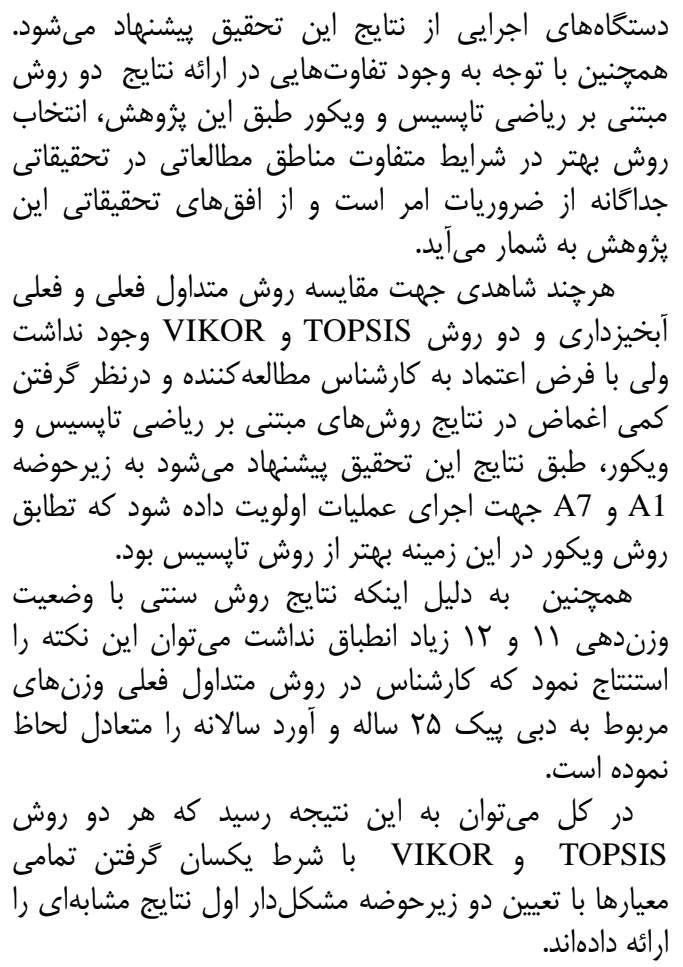

با توجه به اخذ نتايج مشابه در هر سه روش متداول

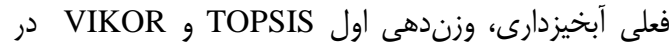

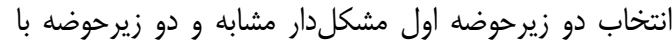

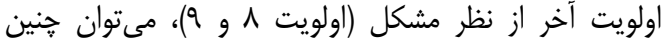

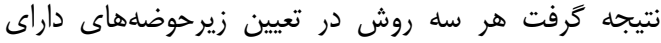

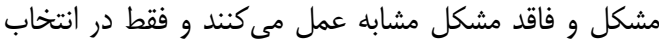

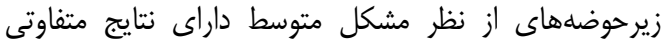

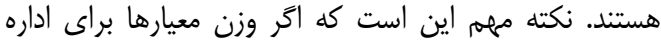

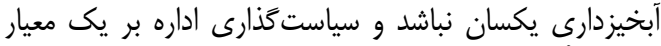

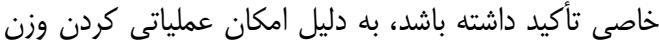

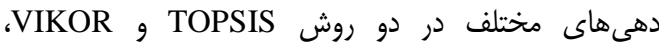

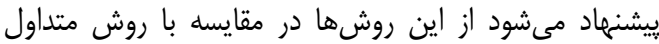

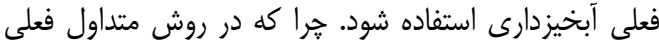

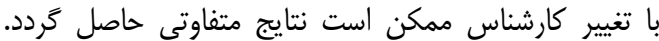

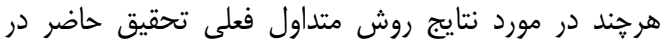

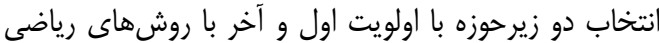

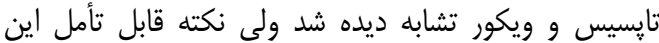

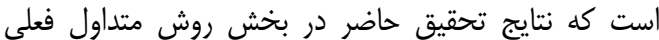

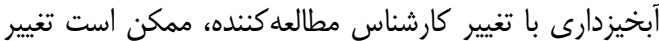

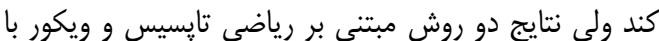

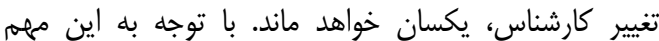

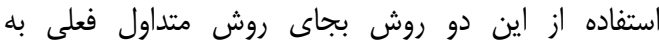
Fuzzy AHP method for native plant type selection and implant (Case Study: Sarcheshmeh copper mine). Journal of Renewable Natural Resource Researches, 2(3): 45-56 (In Persian).

2. Alizadeh. A. 2006. Soil, water, plant relationship. Astan ghods razavi press, $470 \mathrm{pp}$ (In Persian).

3. Asgharpor, M.J. 2014. Multi criteria design making. Tehran university press, 400 pp (In Persian).

4. Bari; F., M.K. Wood and L. Murry. 1995. Livestock grazing impacts on inter rill erosion on Pakistan. Journal of Range Management, 48: 251-257.

5. Chang, C.L. and H. Chung-Hsin. 2009. Multi-criteria analysis via the VIKOR method for prioritizing land-use restraint strategies in the Tseng-Wen reservoir watershed. Journal of Environmental Mmanagement, 90: 3226-3230.

6. Esmaeli, A. and K. Abdollahi. 2010. Watershed management \& soil conservation. University of mohaghegh ardabili press, 578 pp (In Persian).

7. Karami, O., S.M. Hoseini Nasr, H. Jalilvand and M.H. Miryaghobzadeh. 2015. Determination of Babolrood basin capability for various land uses using multi criteria decision making methods. Journal of Watershed Management Research, 6(11):171-181 (In Persian).

8. Kassas, M. 1983. The global biosphere: conservation for survival. Mazingira, 7(2): 2-13.

9. Kaya, T. and C. Kahraman. 2011. Fuzzy multiple criteria forestry decision making based on an integrated VIKOR and AHP approach. Expert Systems with Applications, 38: 7326-7333.

10. Kholghi, M. 2002a. Multicriterion decision making tools for wastewater planning management. Journal of Agricultural Sciences and Technology, 3: 11-21.

11. Kholghi, M. 2002b. The use of MDCM method in prioritizing sub watersheds structural flood control. Iranian Natural Resources Journal, 55(4): 479-490 (In Persian).

12. Kim, Y., E.S. Chung, S.M. Jun and S.U. Kim. 2013. Prioritizing the best sites for treated wastewater in stream use in an urban watershed using fuzzy TOPSIS. Resources, Conservation and Recycling, 73: 23-32.

13. Mehri, A., A.R. Salmanmahiny, S.H.R. Mirkarimi and H.R. Rezaei. 2014. Use of optimization algorithms to prioritize protected areas in Mazandaran Province of Iran. Journal for Nature Conservation, 22: 462-470.

14. Momenian, P., H. Nazarnejhad, M.H. Miryaghoubzadeh and R. Mostafazadeh. 2018. Assessment and Prioritizing of Subwatersheds Based on Watershed Health Scores (Case Study: Ghotorchay, Khoy, West Azerbaijan). Journal of Watershed Management Research, 17(9): 1-13.

15. Mostafazadeh, R., K. Haji., A. Esmali-Ouri and H. Nazarnejad. 2017. Prioritization the Critical SubWatersheds based on Soil Erosion and Sediment using Watershed Erosion Response Model (WERM) and Morphometric Analysis (Case study: Rozechai Watershed, West Azerbaijan Province). Journal of Watershed Management Research, 8(16): 142-156. 
16. Sadeghlo, T. and H. Sobhani Gheidari. 2014. Management alternatives for flood hazard using Topsis model in rural regions (case study: Gharehchay Ramian watershed). Geography and Environmental Hazard, 12: 105-128 (In Persian).

17. Tabtabaei, S.M.F. 2006. Living things. Enteshr sahami nashr press, 384 pp (In Persian).

18. Watershed management office of Kerman, 1392. Synthesis report of Asyabjofteh (provided by engineering incorporation of Sarshakhehayeh sabze Halil, 120 pp (In Persian). 


\title{
Prioritization of Sub-Catchments for Operation of Watershed Management Projects Via Multi-Criteria Decision Making Techniques (Case Study: Asyabjofeth Watershed)
}

\section{Sedigheh Mohamadi}

Department of Ecologv. Institute of Science and High Technology and Environmental Sciences. Graduate University of Advanced Technology, Kerman, Iran (Corresponding Author: mohamadisedigeh@ gmail.com) Received: 21 June 2015 Accepted: 19 June 2016

\begin{abstract}
Few researches about prioritization of sub-watersheds of watersheds were conducted to watershed management operations in the world. Cause of existing of professional intervention in traditional method of watershed management office, this research was carried out to prioritization of sub-watersheds via multi-criteria decision making techniques (TOPSIS and VIKOR method in 12 different weighting conditions) in Asyabjofeth watershed. Problems was divided to 5 criteria as soil erosion and deposition, drought, flood, aridity, socio-economic problem. According to results, first scenario (equal weight of sub criteria) of TOPSIS and VIKOR methods and traditional method conducted same in recognition of two most and least critical sub catchments and differed together in recognition of sub watersheds with moderate critical.
\end{abstract}

Keywords: Prioritization, Multi-criteria decision making techniques, Subwatershed, Baft dam 